\title{
Life Cycle Assessment of Environmental Impact of Steelmaking Process
}

\author{
Huimin Liu $\mathbb{D}^{1},{ }^{1}$ Qiqiang Li $\mathbb{D}^{1},{ }^{1}$ Guanguan Li $\mathbb{D},{ }^{2}$ and Ran Ding $\mathbb{D}^{1}$ \\ ${ }^{1}$ The School of Control Science and Engineering, Shandong University, Jinan 250061, China \\ ${ }^{2}$ Institute of Marine Science and Technology, Shandong University, Qingdao 266237, China3011 \\ Correspondence should be addressed to Qiqiang Li; qqli@sdu.edu.cn
}

Received 23 September 2020; Revised 13 November 2020; Accepted 25 November 2020; Published 3 December 2020

Academic Editor: Rui Wang

Copyright (c) 2020 Huimin Liu et al. This is an open access article distributed under the Creative Commons Attribution License, which permits unrestricted use, distribution, and reproduction in any medium, provided the original work is properly cited.

The steel industry is facing problems such as serious environmental pollution and high resource consumption. At the same time, it lacks effective methods to quantify potential environmental impacts. The purpose of this work is to conduct a specific environmental analysis of steelmaking production in steel plants. The ultimate goal is to discover the main pollution of steelmaking and identify potential options for improving the environment. This paper uses life cycle assessment method to carry out inventory and quantitative analysis on the environmental impact of steelmaking system. Through analysis, the hazards are divided into four major categories, which are human health, climate change, ecosystem quality, and resources. The results show that molten iron has the greatest impact on human health, followed by the greatest impact on resources. The impact of scrap steel on human health ranks third. Molten iron is a key process that affects human health, climate change, ecosystems quality, and resources. In addition, processes such as fuels, working fluids, and auxiliary materials also cause certain environmental damage, accounting for a relatively small proportion. Optimizing the utilization of scrap steel and molten iron resources and improving the utilization efficiency of resources and energy are helpful to reduce the environmental hazards of steelmaking system.

\section{Introduction}

The iron and steel industry is a pillar industry of the national economy and an energy-intensive industry. Energy consumption accounts for an increasing proportion, accounting for about $15 \%$ of the country's total industrial consumption. In the past three decades, crude steel production has more than doubled, reaching 84.26 million tons in 2019. This productivity inevitably imposes an environmental burden on the steelmaking sector. For example, in a country like China, the industry accounts for $12 \%$ of the national $\mathrm{CO}_{2}$ emissions [1].Therefore, the steelmaking process must be analysed in order to have a clear understanding of the main environmental impacts and may involve the implementation of circular economy solution.

At present, there are many researches on the environmental impact assessment of China's steel industry, such as greenhouse gas emission reduction, air pollutant emission reduction, steel wastewater footprint and production capacity, resource and energy emissions, etc. However, the studies mentioned above fail to elucidate the upstream and downstream impacts, whereas life cycle assessment (LCA) is a method of summarizing and evaluating the potential environmental impacts of all inputs and outputs of a system of products (or services) throughout its life cycle. LCA is evaluated based on the contribution of the production process to the environment, including categories such as global warming potential (GWP), land acidification, land occupation, respirable organic, and human toxicity. Therefore, LCA can identify the unit processes with the greatest impact on the environment for targeted improvements [2].

Some studies have also been conducted on life cycle assessment of the steel industry worldwide. Reference [3] also carried out an LCA analysis of the production, selected $1 \mathrm{~kg}$ of metal as a functional unit, and evaluated the environmental impact of steel and stainless steel based on global warming potential, solid waste burden, and total energy 
demand. In a comprehensive study, [4] compared the effects of different steels (slabs, hot-rolled, cold-rolled, hot-dip galvanized, and electrogalvanized steel) on fossil fuels, global warming potential, ecotoxicity, minerals, carcinogens, and respiratory inorganics; the results show that the hot-dip galvanized steel sheet has the greatest impact. In a recent study, [5] has developed a water footprint calculation model and calculated the water footprint of steel from the perspective of life cycle assessment. These data show that the steel plant poses a serious hazard to the water environment. Bieda conducted an inventory analysis on the blast furnace of an integrated steel plant in Krakow, Poland, and collected and sorted out the input and output list of the blast furnace [6]. Including sinter, limestone, etc., energy consumption and fuel include pulverized coal, natural gas, and blast furnace gas. The operating parameters, air pollutant discharge, and heavy metal discharge are given. Bieda performed an analysis of the continuous casting process at the Krakow comprehensive steel plant in Poland, which included not only energy consumption, fuel, materials, and waste but also operational data such as dust, iron, $\mathrm{PM}_{10}$, and waste [7]. This is the basis of life cycle assessment analysis. Korol [8] conducted a life cycle assessment of Polish steel production by integrating steel production. The study pointed out that in the integrated steel production routes the production of pig iron in blast furnaces has the greatest impact on greenhouse gas emissions and fossil fuel consumption, and the sintering process of iron ore is the biggest cause of dust. The substitution of raw materials in the iron making process can effectively reduce the impact of the steel industry on the environment. Manfred comprehensively studies the current evaluation methods impact on resources and points out that it needs to be improved [9]. The three key issues in resource sustainability assessment are renewability, recyclability, and criticality. The model in this study has different representations of the impact on resource depletion and points out the differences in different resource types and scales. Liu used the life cycle assessment method to analyse 12 major iron ore mines and major steel producers, calculated the production intensity per unit of GDP, and finally proposed the problem of pollution distribution among international trade participants [10]. He pointed out that ecotoxicity is the most serious consequence in the steel production chain, which is not negligible compared with the impact of carbon emissions; he also pointed out that importing countries benefiting from pollution-free materials should share the environmental pollution caused by steel processing by trading partners.

In the above studies, the idea of life cycle assessment method is used, but due to different basis, the results are still not comparable. In addition, the impact categories considered in these studies cannot be compared with each other. Therefore, this study aims to make an accurate environmental analysis of a steel production in Shandong, China, and find out the improvement process. It uses specific scene data on-site to conduct LCA assessment of steel production in steel plants. The organization of this article is as follows: the next section explains the main LCA methods and inventories. Section 3 explains the results of the environmental impact assessment. In the last part, the results are discussed and some conclusions are drawn.

\section{Materials and Methods}

2.1. System Boundaries. The complete life cycle of a product is usually divided into the following stages [11]: (1) cradle to entry (raw material extraction and refining); (2) factory door to factory door (product manufacturing); and (3) factory door to grave (product use, recycling, and disposal). Due to the many uncertain factors caused by the LCA evaluation of product use, recycling, and disposal, in order to reduce the complexity of LCA evaluation and improve its operability, the selected boundary definition is "from cradle to factory door." According to the ingredients requirements, first put scrap steel into the furnace, then pour molten iron, and add appropriate slagging materials (such as quicklime, etc.). After feeding, insert the oxygen spray gun into the furnace from the top of the furnace and blow in oxygen to make it directly oxidize with the hot molten iron to remove impurities. When the composition and temperature of the molten steel meet the requirements, the steel can be tapped. All the materials and energy consumed by the production equipment involved in the process of steelmaking from the molten iron entering the steelmaking station, smelting into molten steel through the converter, and leaving the converter are taken into account. A ton of crude steel is used as the functional unit of the present study, in order to provide life cycle inventory (LCI) and all the results of quantitative standards [11]. The boundary definition of the steelmaking system in this study is shown in Figure 1. Scrap steel, molten iron, and waste treatment are involved (i.e., wastewater treatment, solid waste treatment in landfills, hazardous waste incineration, and air emission control). Each process considers the input of raw materials, transportation, energy generation, and consumption (for example, coal-based electricity, coal, and coke), direct waste emissions (for example, dust, nickel, $\mathrm{SO}_{2}$, and $\mathrm{NO}_{\mathrm{x}}$ ), and land occupation.

2.2. Data Source and Life Cycle Inventory. Inventory analysis uses a survey model to collect and classify the raw materials, transportation, energy, infrastructure, direct discharge, and waste disposal in different steps of each process. In this study, most of the analysis data of energy resource consumption and pollutant emission inventory of the steelmaking system (obtained 1t molten steel products) was collected from a group company in Shandong Province, and part of the data was derived from literature [12] and the cleaner production (HJ/T294-2006, HJ/T426-2008, HJ/T 1262003, HJ/T 427-2008, HJ/T 428-2008, and HJ/T 3182006) secondary indicators [13]. The life cycle list of molten steel products is shown in Table 1.

2.3. Life Cycle Impact Assessment Methodology. The steps of life cycle impact assessment are characterization, damage assessment, normalization, and single scoring. In the impact method, damage is divided into fifteen midpoint categories 


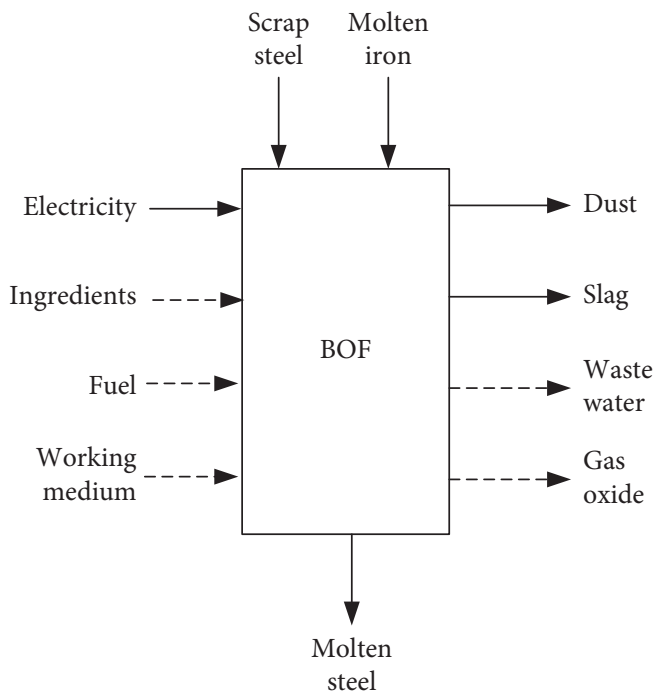

FIGURE 1: Simplified scheme of iron and steel production routes and processes.

TABle 1: Life cycle inventories of molten steel. Value are presented per ton.

\begin{tabular}{|c|c|c|c|c|}
\hline Inputs and outputs & Categories & Normal production & Clean production & Unit \\
\hline Molten iron & & 1008 & 947 & $\mathrm{~kg}$ \\
\hline Scrap steel & & 70.43 & 78 & $\mathrm{~kg}$ \\
\hline Electricity & & 26.65 & $25 \mathrm{~s}$ & kWh \\
\hline \multirow{3}{*}{ Ingredients } & Quicklime & 50 & 50 & $\mathrm{~kg}$ \\
\hline & $\mathrm{Fe}$ & 20 & 20 & $\mathrm{~kg}$ \\
\hline & Dolomite & 20 & 20 & $\mathrm{~kg}$ \\
\hline \multirow[b]{2}{*}{ Fuel } & Coke oven gas & 0.16 & 0.16 & $\mathrm{~m}^{3}$ \\
\hline & BOF gas & 12.15 & 12.15 & $\mathrm{~m}^{3}$ \\
\hline \multirow{5}{*}{ Working medium } & Oxygen & 37.28 & 37.28 & $\mathrm{~m}^{3}$ \\
\hline & Nitrogen & 45.12 & 45.12 & $\mathrm{~m}^{3}$ \\
\hline & Argon & 75.2 & 75.2 & $\mathrm{~m}^{3}$ \\
\hline & Air & 15.38 & 15.38 & $\mathrm{~m}^{3}$ \\
\hline & Pure water & 2.7 & 2.7 & $\mathrm{~m}^{3}$ \\
\hline \multirow{12}{*}{ Emission } & $\mathrm{CO}_{2}$ & 28.28 & 28.28 & $\mathrm{~kg}$ \\
\hline & $\mathrm{SO}_{2}$ & 5.75 & 5.75 & $\mathrm{~g}$ \\
\hline & $\mathrm{NO}_{2}$ & 3.84 & 3.84 & $\mathrm{~g}$ \\
\hline & $\mathrm{CO}$ & 4.6 & 4.6 & $\mathrm{~kg}$ \\
\hline & Waste water & 1.07 & 1.07 & $\mathrm{~m}^{3}$ \\
\hline & Dust & 135 & 135 & $\mathrm{~kg}$ \\
\hline & $\mathrm{Cd}$ & 50 & 50 & $\mathrm{mg}$ \\
\hline & $\mathrm{Cr}$ & 120 & 120 & $\mathrm{mg}$ \\
\hline & $\mathrm{Cu}$ & 3090 & 3090 & $\mathrm{mg}$ \\
\hline & $\mathrm{Ni}$ & 280 & 280 & $\mathrm{mg}$ \\
\hline & $\mathrm{Pb}$ & 930 & 930 & $\mathrm{mg}$ \\
\hline & $\mathrm{Zn}$ & 7500 & 7500 & $\mathrm{mg}$ \\
\hline
\end{tabular}

[14] (carcinogens, noncarcinogens, respiratory inorganics, ionizing radiation, ozone layer depletion, respiratory organics, aquatic ecotoxicity, terrestrial ecotoxicity, terrestrial acid/nutrition, land occupation, aquatic acidification, aquatic eutrophication, global warming, nonrenewable energy, and mineral extraction), and for the convenience of explanation, the 15 midpoints are classified into four endpoint categories (human health, ecosystem quality, climate change, and resources). In this way, you can not only see the impact value of the midpoint category, but also intuitively see the final impact on the environment [15]. In this paper, the software SimaPro is used for calculation and the Impact $2002+$ method is adopted.

\section{Results and Discussion}

Table 2 lists the life cycle inventory assessment (LCIA) midpoint results based on functional units. According to climate change, the midpoint of LCIA for the production of 1 ton of molten steel is $358.84 \mathrm{~kg} \mathrm{CO}$ equivalent, for aquatic acidification is $1.96 \mathrm{~kg}$ 
TABLe 2: Life cycle assessment midpoint results of molten steel.

\begin{tabular}{|c|c|c|c|c|c|c|c|c|}
\hline Categories & Unit & Total & Electricity & Scrap steel & Ingredients & Fuel & Molten iron & Working medium \\
\hline Carcinogens & $\mathrm{kg} \mathrm{C}_{2} \mathrm{H}_{3} \mathrm{Cl}$ eq & 16.93 & 0.05 & 7.22 & 3.43 & 0.70 & 5.01 & 0.52 \\
\hline Noncarcinogens & $\mathrm{kg} \mathrm{C}{ }_{2} \mathrm{H}_{3} \mathrm{Cl}$ eq & 158.18 & 0.75 & 73.35 & 16.97 & 0.03 & 66.43 & 0.65 \\
\hline Respiratory inorganics & $\mathrm{kg} \mathrm{PM}_{2.5} \mathrm{eq}$ & 0.42 & 0.01 & 0.04 & 0.05 & 0.01 & 0.27 & 0.05 \\
\hline Ionizing radiation & Bq C-14 eq & 11990.73 & 77.76 & 0.00 & 425.30 & 19.96 & 5479.27 & 5988.44 \\
\hline Ozone layer depletion & $\mathrm{kg}$ CFC-11 eq & 0.00 & 0.00 & 0.00 & 0.00 & 0.00 & 0.00 & 0.00 \\
\hline Respiratory organics & $\mathrm{kg} \mathrm{C} \mathrm{H}_{4} \mathrm{eq}$ & 0.21 & 0.00 & 0.03 & 0.01 & 0.02 & 0.14 & 0.01 \\
\hline Aquatic ecotoxicity & $\mathrm{kg}$ TEG water & 8102543.87 & 84954.23 & 38796.06 & 55164.71 & 244.41 & 7865355.15 & 58029.32 \\
\hline Terrestrial ecotoxicity & kg TEG soil & 21450.23 & 68.07 & 16273.15 & 555.35 & 60.84 & 4089.03 & 403.79 \\
\hline Terrestrial acid/nitrification & $\mathrm{kg} \mathrm{SO}_{2}$ eq & 7.12 & 0.23 & 0.58 & 1.28 & 0.09 & 4.07 & 0.87 \\
\hline Land occupation & $\mathrm{m}^{2} \mathrm{a}$ & 10.68 & 0.13 & 0.98 & 1.51 & 0.04 & 6.98 & 1.05 \\
\hline Aquatic acidification & $\mathrm{kg} \mathrm{SO}_{2}$ eq & 1.96 & 0.08 & 0.16 & 0.38 & 0.02 & 0.95 & 0.37 \\
\hline Aquatic eutrophication & $\mathrm{kg} \mathrm{PO}_{4}{ }^{3-} \mathrm{eq}$ & 0.13 & 0.00 & 0.00 & 0.00 & 0.00 & 0.13 & 0.00 \\
\hline Global warming & $\mathrm{kg} \mathrm{CO} \mathrm{Cq}^{\mathrm{T}}$ & 358.54 & 25.68 & 56.22 & 91.71 & 5.30 & 120.63 & 59.01 \\
\hline Nonrenewable energy & MJ primary & 27914.93 & 293.34 & 543.59 & 794.31 & 96.03 & 24870.01 & 1317.65 \\
\hline Mineral extraction & MJ surplus & 3.25 & 0.02 & 0.24 & 2.09 & 0.01 & 0.58 & 0.30 \\
\hline
\end{tabular}

$\mathrm{SO}_{2}$, and for respiratory inorganics $0.42 \mathrm{~kg} \mathrm{PM}_{2.5}$ equivalent; the detailed values of 15 midpoints are shown in Table 2 .

In order to compare the different impact categories of each midpoint and analyse the impact of each midpoint type on the overall situation, this study conducted a normalized analysis. The normalized midpoint results of each functional unit are shown in Figure 2. Two situations are considered: normal production and clean production. The difference is the ratio of scrap steel and molten iron in the production process. The cleaner production scene uses more steel scrap and less molten iron. It is worth noting that in both cases, the waste disposal method is assumed to be the same. In the environmental impact category, especially nonrenewable resources, respiratory inorganics, toxicity of aquatic organisms, and terrestrial ecotoxicity, the scene of normal production is significantly higher than the scene of cleaner production. These findings may be attributed to the fact that normal production requires more molten iron, which requires more fuel and ore, which will inevitably produce more waste water, waste gas, and slag during the treatment process. It also shows that recycling of scrap steel is a more scientific production method.

Table 3 and Figure 3 show the life cycle evaluation endpoint of the steelmaking system, which is obtained by classifying and weighing all intermediate damage types. It can be seen from Figure 3 that molten iron, scrap steel, and auxiliary materials have a greater impact on the environment. Among them, molten iron has a greater damage value to natural resources, human health, and the ecological environment. The damage value of scrap steel to human health is greater. It can be seen from Figure 3 that steel scrap and molten iron still have the greatest impact, which is basically consistent with the results [16]. In Figure 3, molten iron is the most harmful to natural resources, accounting for about $60 \%$. Scrap steel is the most harmful to human health, which is about $60 \%$. The impact of auxiliary materials and working fluids on the environment is second, and the impact of electricity and fuel is negligible.

3.1. Main Process. According to the results of normalization evaluation, the most important potential environmental impacts during the entire life cycle of molten steel products are noncarcinogens, nonrenewable energy, terrestrial ecotoxicity, global warming, respiratory organics, carcinogens, and aquatic ecotoxicity. Therefore, it is necessary to identify and analyse the key processes that cause the above environmental impacts, so as to put forward relevant recommendations. On the basis of the evaluation results of the midpoint in the life cycle, the key processes are identified, and the results are shown in Figure 4. It can be seen from Figure 4 that for the abovementioned impact categories, scrap steel and electricity are the most important environmental contributing factors, and their impact on most environmental categories accounts for more than 50\%. Scrap steel has a particularly significant impact on noncarcinogens, terrestrial ecotoxicity, and carcinogens, and its contribution can reach more than $85 \%$ of its total environmental impact. It also has a significant impact on global warming and breathing organic matter. At the same time, the contribution of electricity to nonrenewable energy and aquatic ecotoxicity cannot be ignored.

3.2. Main Contributors. Based on the identification of main processes, this study also identifies the main substances in each main influence category, so as to put forward relevant opinions on the consumption of certain substance or pollutant discharge. This study identified the four key substances of environmental impact types in the endpoint evaluation, and the results are shown in Figure 5. Figure 5 shows the specific substances that contribute significantly to each major environmental category and their contribution rates. For the environmental impact of human health, coke accounts for $23 \%$, iron ore for $22 \%$, and residue for $17 \%$, which is consistent with the serious pollution impact of molten iron. Coke and coal are the two substances that have the greatest impact on the ecosystem. It can be seen that the two are not clean production methods, and the proportion of clean energy should be increased. The key material in the potential environmental impact of climate change is scrap steel, which accounted for $28 \%$, followed by coke and ore. Coke ore produces a large amount of carbon oxides, sulfur oxides, and nitrogen oxides during the smelting process, 


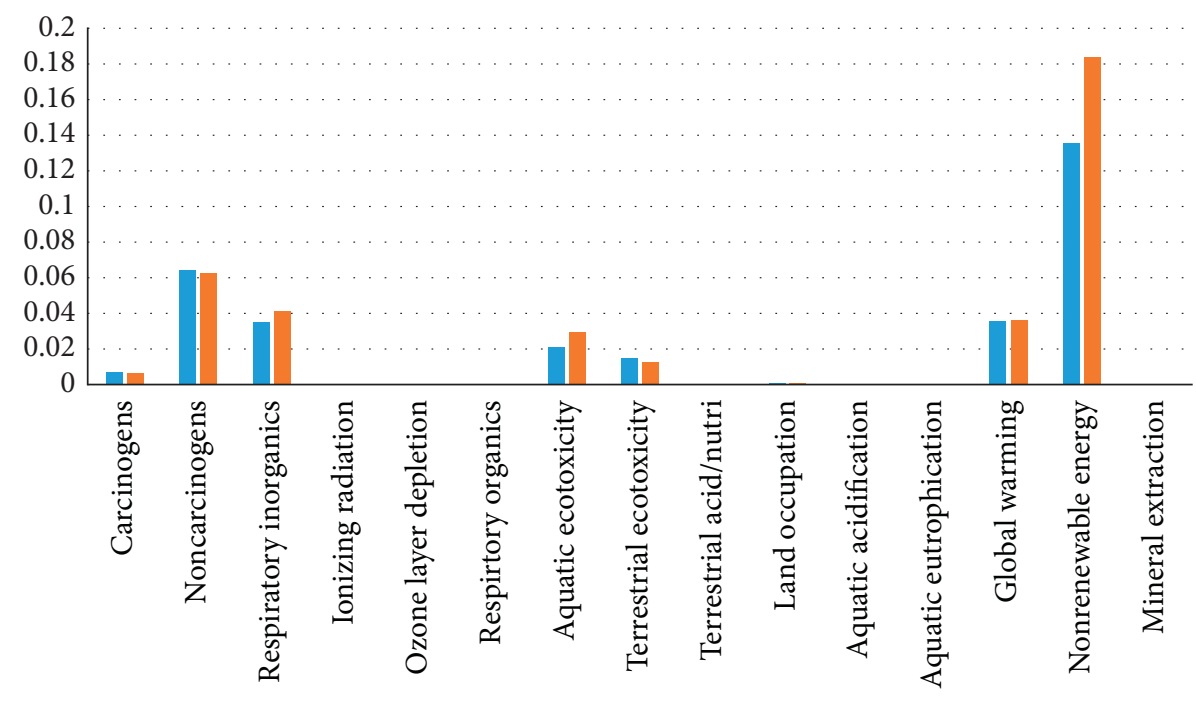

Clean production

Normal production

Figure 2: Normalized midpoint results.

TABLe 3: Life cycle assessment endpoint results of molten steel.

\begin{tabular}{lcccccccc}
\hline Categories & Unit & Total & Electricity & Scrap steel & Ingredients & Fuel & Molten iron & Working medium \\
\hline Total & $\mathrm{Pt}$ & $3.74 E-01$ & $6.25 E-03$ & $5.48 E-02$ & $2.78 E-02$ & $2.40 E-03$ & $2.63 E-01$ & $2.04 E-02$ \\
Human health & $\mathrm{Pt}$ & $1.11 E-01$ & $1.35 E-03$ & $3.59 E-02$ & $1.25 E-02$ & $1.18 E-03$ & $5.48 E-02$ & $5.22 E-03$ \\
Ecosystem quality & $\mathrm{Pt}$ & $4.35 E-02$ & $3.79 E-04$ & $9.66 E-03$ & $7.40 E-04$ & $4.57 E-05$ & $3.20 E-02$ & $5.95 E-04$ \\
Climate change & $\mathrm{Pt}$ & $3.62 E-02$ & $2.59 E-03$ & $5.68 E-03$ & $9.26 E-03$ & $5.35 E-04$ & $1.22 E-02$ & $5.96 E-03$ \\
Resources & $\mathrm{Pt}$ & $1.84 E-01$ & $1.93 E-03$ & $3.58 E-03$ & $5.24 E-03$ & $6.32 E-04$ & $1.64 E-01$ & $8.67 E-03$ \\
\hline
\end{tabular}

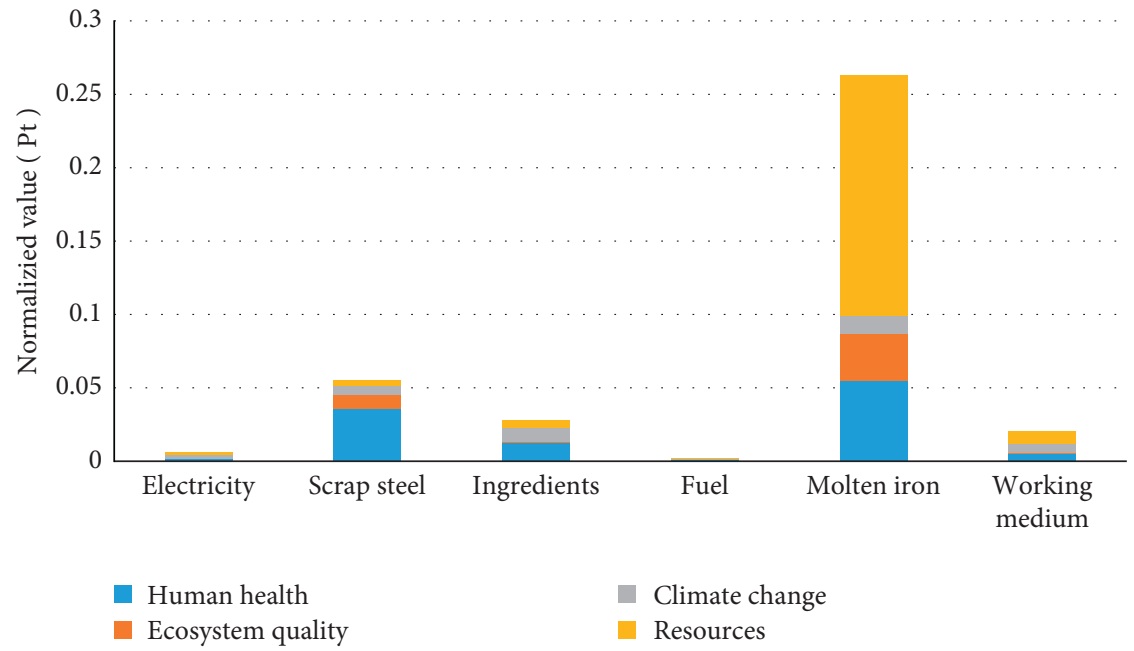

Figure 3: Single score result for 1t molten steel.

which has a greater adverse impact on the climate. Among the potential environmental impacts of natural resource damage, coke accounts for $52 \%$ and coal accounts for $37 \%$, indicating that they not only have a greater impact on the above mentioned types, but also have a greater impact on natural resources. The development of clean energy is of great significance for the reduction of environmental impact in the steelmaking process.
3.3. Sensitivity and Uncertainty Analysis. Sensitivity analysis is a key part of LCA testing the sensitivity of LCI input data, which can be calculated [17] based on the percentage adjustment rule of input and output parameters (ISO 14044, 2006; ISO 14040, 2006). A sensitivity analysis was performed by changing $5 \%$ of the material input at a time [18].

Table 4 lists the results of the sensitivity analysis of the main contributors, aiming to determine the main impact on 


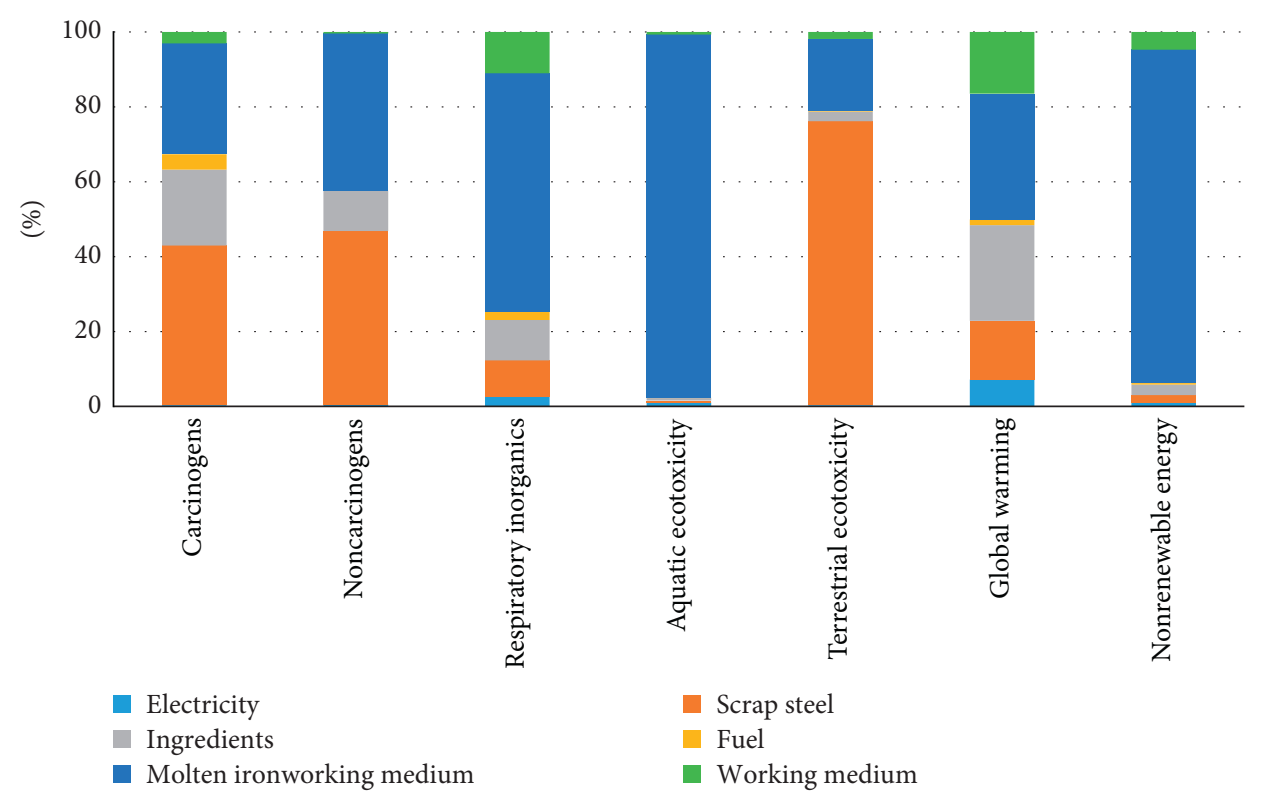

FIgURE 4: Main process that contribute to significantly affected categories.

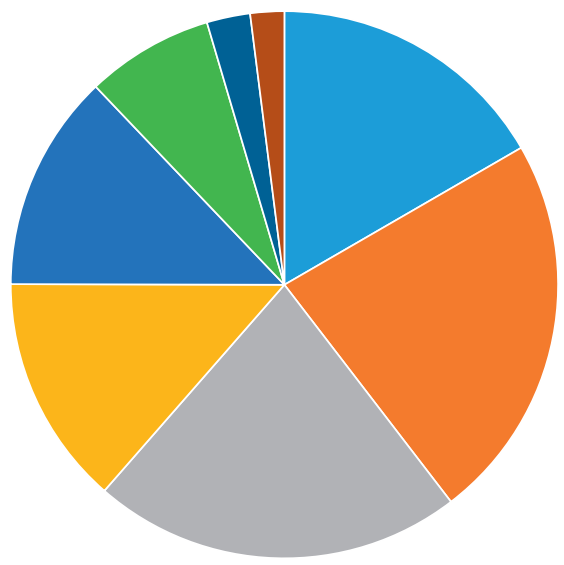

Residue

Coal cokes S

Nonferrous metal ores

Coal from open mine $S$

Gypsum, mineral, at mine/CH S

Steel I

Iron and ferroalloy ores

Argon ETH S

(a)

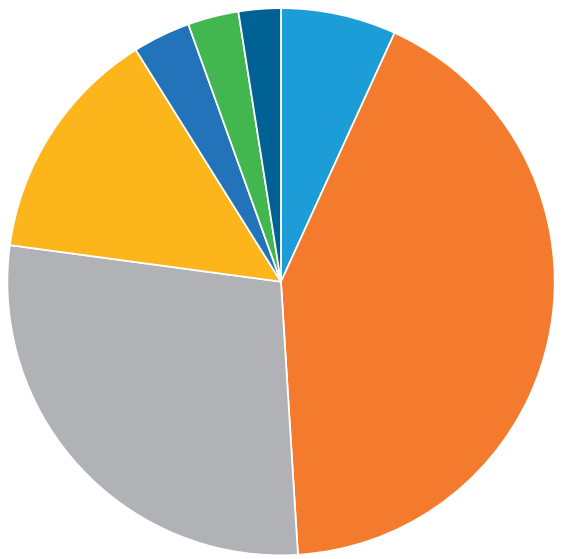

Residue

Coal cokes S

Coal from open mine $S$

Copper ore

Gypsum, mineral

Nonferrous metal ores

Iron and ferroalloy ores

(b)

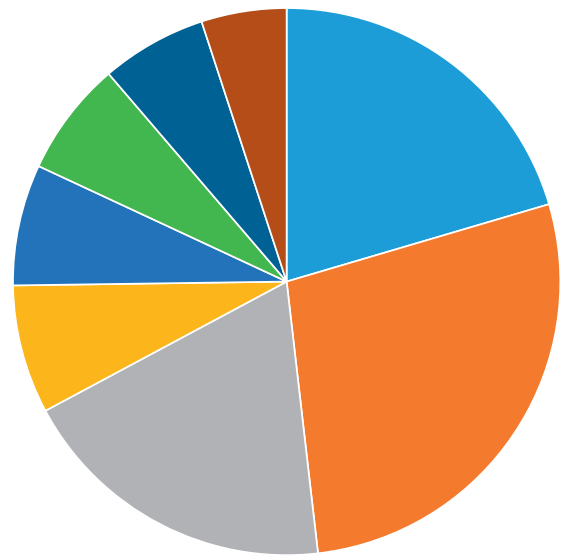

Residue

Coal cokes S

Lime (burnt) ETH S

Iron and steel forgings

Electricity coal power plant

Argon ETH S

Figure 5: Continued. 


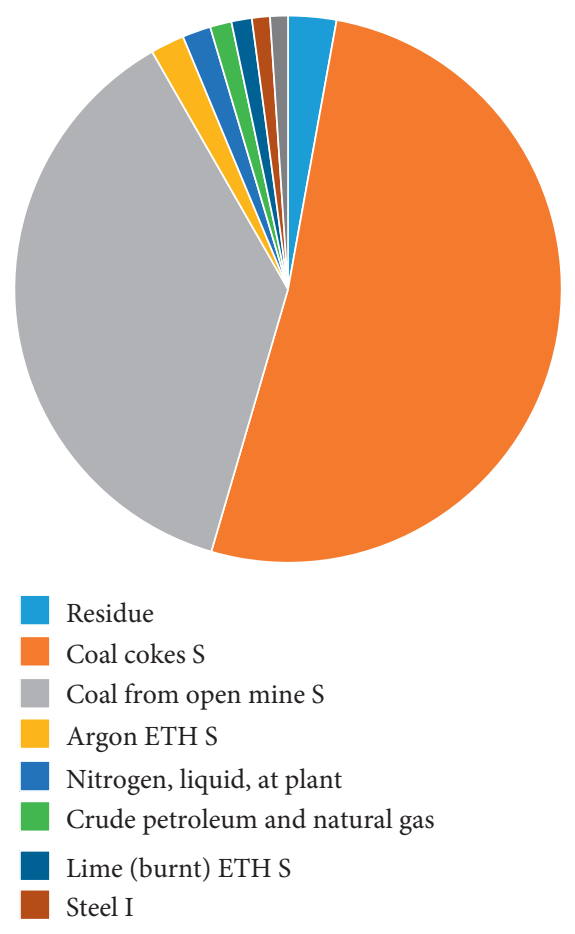

(d)

FiguRE 5: Contributions of the most significant substances to key categories. (a) Human health, (b) ecosystem quality, (c) climate change, and $(\mathrm{d})$ resource.

TABLE 4: Sensitivity analysis.

\begin{tabular}{|c|c|c|c|c|}
\hline Categories & Unit & Molten iron $5 \%$ & Scrap steel $5 \%$ & Electricity $5 \%$ \\
\hline Carcinogens & $\mathrm{kg} \mathrm{C}_{2} \mathrm{H}_{3} \mathrm{Cl}$ eq & $2.51 E-01$ & $3.61 E-01$ & $2.67 E-03$ \\
\hline Noncarcinogens & $\mathrm{kg} \mathrm{C} \mathrm{C}_{3} \mathrm{Cl}$ eq & $3.32 E+00$ & $3.67 E+00$ & $3.75 E-02$ \\
\hline Respiratory inorganics & $\mathrm{kg} \mathrm{PM}_{2.5} \mathrm{eq}$ & $1.34 E-02$ & $2.05 E-03$ & $5.26 E-04$ \\
\hline Ionizing radiation & $\mathrm{Bq} C-14 \mathrm{eq}$ & $2.74 E+02$ & $0.00 E+00$ & $3.91 E+00$ \\
\hline Ozone layer depletion & $\mathrm{kg}$ CFC-11 eq & $2.03 E-06$ & $2.06 E-06$ & $1.21 E-07$ \\
\hline Respiratory organics & $\mathrm{kg} \mathrm{C}_{2} \mathrm{H}_{4}$ eq & $6.90 E-03$ & $1.52 E-03$ & $1.85 E-04$ \\
\hline Aquatic ecotoxicity & $\mathrm{kg}$ TEG water & $3.93 E+05$ & $1.94 E+03$ & $4.27 E+03$ \\
\hline Terrestrial ecotoxicity & kg TEG soil & $2.05 E+02$ & $8.14 E+02$ & $3.42 E+00$ \\
\hline Terrestrial acid/nutrition & $\mathrm{kg} \mathrm{SO}_{2}$ eq & $2.04 E-01$ & $2.91 E-02$ & $1.18 E-02$ \\
\hline Land occupation & $\mathrm{m}^{2} \mathrm{a}$ & $3.49 E-01$ & $4.90 E-02$ & $6.77 E-03$ \\
\hline Aquatic acidification & $\mathrm{kg} \mathrm{SO} \mathrm{Seq}$ & $4.74 E-02$ & $8.06 E-03$ & $3.81 E-03$ \\
\hline Aquatic eutrophication & $\mathrm{kg} \mathrm{PO}_{4}{ }^{3}-\mathrm{eq}$ & $6.38 E-03$ & $4.79 E-05$ & $6.92 E-05$ \\
\hline Global warming & $\mathrm{kg} \mathrm{CO} \mathrm{Cq}_{2}$ & $6.03 E+00$ & $2.81 E+00$ & $1.29 E+00$ \\
\hline Nonrenewable energy & MJ primary & $1.24 E+03$ & $2.72 E+01$ & $1.47 E+01$ \\
\hline Mineral extraction & MJ surplus & $2.89 E-02$ & $1.22 E-02$ & $1.13 E-03$ \\
\hline
\end{tabular}

the LCIA results obtained in this study. The comparison of LCIA results in the steelmaking process shows that a $5 \%$ reduction in power consumption will result in a reduction of carbon dioxide emissions by about $1.29 \mathrm{~kg} \mathrm{CO}$ equivalent, and the nonrenewable energy is $1.47 \mathrm{MJ}$ equivalent. For other scenarios and categories, similar analysis can be made using the sensitivity results shown in Table 4 . The three main processes have the greatest impact on nonrenewable energy, global warming effect, and soil acidification. Among them, changes in molten iron have the greatest overall impact on the environment, followed by scrap steel and electricity. It can be seen that reducing the use of molten iron and developing cleaner steel production can effectively reduce environmental pollution.

Table 5 shows the probability comparison of different scenes performed using Monte Carlo simulation. The probability that cleaner production scenario has a higher global warming effect score than normal production is $43 \%$, which means that the impact of cleaner production on global warming is lower than normal production. A similar situation can be observed from the uncertainty analysis results shown in Table 5. In general, except for carcinogens and land 
TABLe 5: Uncertainty analysis.

\begin{tabular}{lc}
\hline Categories & $\begin{array}{c}\text { Clean production } \geq \text { normal production } \\
(\%)\end{array}$ \\
\hline Aquatic acidification & 20 \\
Aquatic ecotoxicity & 2 \\
Aquatic eutrophication & 2 \\
Carcinogens & 65 \\
Global warming & 43 \\
Ionizing radiation & 29 \\
Land occupation & 13 \\
Mineral extraction & 53 \\
Noncarcinogens & 54 \\
Nonrenewable energy & 3 \\
Ozone layer depletion & 44 \\
Respiratory inorganics & 12 \\
Respiratory organics & 9 \\
Terrestrial acid/ & 15 \\
nutrition & 98 \\
Terrestrial ecotoxicity & \\
\hline
\end{tabular}

eutrophication, in most categories, cleaner production scenarios have the lowest environmental burden. Among the 15 impact categories, eleven categories are less than 50\%, which means that the environmental impact of cleaner production is much lower than that of normal production.

\section{Conclusions}

According to the analysis and comparison of the abovementioned molten steel production process, it can be found that molten iron has the most significant impact on the environment, accounting for $70 \%$ of the overall impact, of which the harm to resources can reach $89 \%$, and its environmental load mainly comes from noncarcinogenic substances, terrestrial ecotoxicity, and global warming. Secondly, the impact of scrap steel on the environment accounts for $15 \%$, and the damage to human health is about $32 \%$. Its environmental load mainly comes from nonrenewable energy, respirable inorganic substances, and aquatic ecotoxicity. In contrast, the impact of auxiliary materials and working fluids is small, and the environmental impact of electricity and fuel is the smallest.

In the entire life cycle of molten steel products, the most important categories are as follows: nonrenewable energy, accounting for $49 \%$, and $17 \%$ are noncarcinogens, $11 \%$ are respiratory organics, then terrestrial ecotoxicity, global warming, carcinogens, and aquatic ecotoxicity.

The IMPACT 2002+ method classifies the complex environmental impacts into four types of damage and applies the assessment results to the development and utilization of iron ore resources and ecological environment planning, which is conducive to the decision makers to make correct judgments. Comparing the environmental loads of different processes can also provide a scientific basis for decision makers and lay a foundation for product ecological design and cleaner production.

Of course, since the current research history of life cycle environmental impact assessment is not long, its methodology system is not perfect, there are many differences in the research of scholars in various countries, and there are few application fields in China, so there must be some limitations, such as the variability of the source of the life cycle inventory (different production processes of the same product); the uncertainty of the model used (such as the migration and transformation of pollutants in the environment is simplified through the multimedia model); the uncertainty of the selection in the life cycle analysis (for example, which allocation method and system boundary are used), etc. However, the life cycle environmental impact assessment (LCEA) provides a preliminary analysis of the energy and environmental problems in steel production and provides a good scientific basis for optimizing the development of the industry. Therefore, it is necessary to learn from the experience of international application of life cycle assessment method, accelerate its promotion and application, and truly realize the service for sustainable development.

\section{Data Availability}

The data used to support the findings of this study are available from the corresponding author upon request.

\section{Conflicts of Interest}

The authors declare that there are no conflicts of interest regarding the publication of this paper.

\section{Acknowledgments}

This work was supported by the National Science Foundation of China (61803174) and Shandong Provincial Natural Science Foundation (ZR2019BF024).

\section{References}

[1] W. Chen, X. Yin, and D. Ma, “A bottom-up analysis of China's iron and steel industrial energy consumption and $\mathrm{CO}_{2}$ emissions," Applied Energy, vol. 136, pp. 1174-1183, 2014.

[2] C. Li, H. Bai, Y. Lu, J. Bian, Y. Dong, and H. Xu, "Life-cycle assessment for coal-based methanol production in China," Journal of Cleaner Production, vol. 188, pp. 1004-1017, 2018.

[3] T. E. Norgate, S. Jahanshahi, and W. J. Rankin, "Assessing the environmental impact of metal production processes," Journal of Cleaner Production, vol. 15, no. 8-9, pp. 838-848, 2007.

[4] R. Tongpool, A. Jirajariyavech, C. Yuvaniyama, and T. Mungcharoen, "Analysis of steel production in Thailand: environmental impacts and solutions," Energy, vol. 35, no. 10, pp. 4192-4200, 2010.

[5] Y. Gu, J. Xu, A. A. Keller et al., "Calculation of water footprint of the iron and steel industry: a case study in eastern China," Journal of Cleaner Production, vol. 92, pp. 274-281, 2015.

[6] B. Bieda, "Life cycle inventory processes of the mittal steel Poland (msp) S.A. In Krakow, Poland-blast furnace pig iron production-a case study," International Journal of Life Cycle Assessment, vol. 17, no. 6, pp. 787-794, 2012.

[7] B. Bieda, I. Skalna, B. Gawel, K. Grzesik, A. Henclik, and D. Sala, "Life cycle inventory processes of the integrated steel plant (ISP) in Krakow, Poland-continuous casting of steel (Ccs): a case study," The International Journal of Life Cycle Assessment, vol. 23, pp. 1274-1285, 2018. 
[8] D. Burchart-Korol, "Life cycle assessment of steel production in Poland: a case study," Journal of Cleaner Production, vol. 54, pp. 235-243, 2013.

[9] R. A. F. Alvarenga, K.-H. Erb, H. Haberl, S. R. Soares, R. Van Zelm, and J. Dewulf, "Global land use impacts on biomass production-a spatial-differentiated resource-related life cycle impact assessment method," International Journal of Life Cycle Assessment, vol. 20, no. 4, pp. 440-450, 2015.

[10] Y. Liu, H. Li, S. Huang, H. An, R. Santagata, and S. Ulgiati, "Environmental and economic-related impact assessment of iron and steel production. A Call for shared responsibility in global trade," Journal of Cleaner Production, vol. 269, Article ID 122239, 2020.

[11] M. Finkbeiner, A. Inaba, R. B. H. Tan, K. Christiansen, and H. J. Klueppel, "The new international standards for life cycle assessment: Iso 14040 and Iso 14044," The International Journal of Life Cycle Assessment, vol. 11, no. 2, pp. 80-85, 2006.

[12] X. Li, W. Sun, L. Zhao, and J. Cai, "Material metabolism and environmental emissions of BF-BOF and EAF steel production routes," Mineral Processing and Extractive Metallurgy Review, vol. 39, pp. 50-58, 2018.

[13] China Nonferrous Metals Industry Yearbook, China Nonferrous Metals Industry Yearbook Editorial Board 2014, China Nonferrous Metals Industry, Beijing, China, 2014.

[14] M. Margni, R. Charles, S. Humbert, J. Payet, and O. Jolliet, "Impact 2002+: a new life cycle impact assessment methodology," Int.j.life Cycle Assess, vol. 8, no. 6, pp. 324-330, 2003.

[15] M. Owsianiak, A. Laurent, A. Bjorn, and M. Z. Hauschild, "Impact 2002+, recipe 2008 and Ilcd's recommended practice for characterization modelling in life cycle impact assessment: a case study-based comparison," International Journal of Life Cycle Assessment, vol. 19, no. 5, pp. 1007-1021, 2014.

[16] G. M. Olmez, F. B. Dilek, T. Karanfil, and U. Yetis, "The environmental impacts of iron and steel industry: a life cycle assessment study," Journal of Cleaner Production, vol. 130, pp. 195-201, 2016.

[17] J. Hong, Z. Yu, W. Shi, J. Hong, C. Qi, and L. Ye, "Life cycle environmental and economic assessment of lead refining in China," The International Journal of Life Cycle Assessment, vol. 22, pp. 909-918, 2016.

[18] Q. Wang, W. Liu, X. Yuan et al., "Environmental impact analysis and process optimization of batteries based on life cycle assessment," Journal of Cleaner Production, vol. 174, pp. 1262-1273, 2018. 